\title{
Study of the P-Type Doping Properties of ZnS Nanocrystals
}

\author{
Xiying Ma \\ School of Mathmatics and Physics, Suzhou University of Science and Technology, 1701 Binhe Road, Suzhou, Jiangsu 215011, China \\ Correspondence should be addressed to Xiying Ma, maxy@usx.edu.cn
}

Received 24 April 2010; Accepted 11 July 2010

Academic Editor: Quanqin Dai

Copyright ( 2011 Xiying Ma. This is an open access article distributed under the Creative Commons Attribution License, which permits unrestricted use, distribution, and reproduction in any medium, provided the original work is properly cited.

The paper presents the study of p-type doping properties of ZnS nanocrystals (Ncs) using the local density approximation theory (LDA). Doping with single species of N, P, or As, ZnS nanocrystals are found to have a low-doping concentration and efficiency, which may be limited by the large expelling effect between $\mathrm{Zn}$ and impurity atoms and the compensation action from interstitial $\mathrm{Zn}_{\text {int }}$ atoms that can offer donor states to compensate the acceptors. To decrease the expelling and the compensation effect, composite dopants, such as $\mathrm{N}$ jointed with $\mathrm{Ga}$, In, or $\mathrm{Al}$, are applied to codope $\mathrm{ZnS}$ nanocrystals. As a result, ZnS nanocrystals in p-type with high doping density and efficient are completed.

\section{Introduction}

ZnS nanocrystals, with unique optical properties and a direct band gap of $3.68 \mathrm{eV}$ at room temperature, have great potential applications in fabrication of short-wavelength light-emitting devices (LED) and blue injection-laser diodes (LD) [1-3]. To fabricate nanoscaled devices, semiconductor nanocrystals need to be doped in p-, n-types firstly. And the performance of devices depends on the doping types and doping concentration [4]. Doping with other special impurities, semiconductors will not only enhance their conductivity significantly but also exhibit many novel photoelectric properties [5-7]. For semiconductor nanocrystals, however, the doping concentration and steady are much low than that of the bulk materials. The volume of nanocrystals is so small that it limits the doping concentration and allows the doped impurities to easily escape from it.

Also, doping with other metallic ions, the photoelectric properties of $\mathrm{ZnS}$ nanocrystals will be widely adjusted and improved [8]. However, it is found that they are easily doped for n-type but hard for p-type [9]. This occurs because a $\mathrm{Zn}$ atom in $\mathrm{ZnS}$ very easily departs from its lattice site to become an interstitial $\mathrm{Zn}_{\text {int }}$ atom, which makes $\mathrm{ZnS}$ displaying an intrinsic property of n-type. On the other hand, from the point of system energy, n-type doping will low the system energy while p-type doping will raise it based on the calculation of the first-principle. At the same time, $\mathrm{Zn}_{\text {int }}$ atoms will lift the lattice energy as well. Therefore, ZnS nanocrystals have more difficult in p-type doping $[10,11]$. Now, this problem has become a large barrier for their practical use and delayed the development of new nanodevices. Many theoretical and experimental works have been done on the doping problems for $\mathrm{ZnS}$ nanocrystals, especially for p-type doping [12-14]. Although some succeeded, the doping concentration and steady still do not meet the requirement of devices. In the present study, we investigate the p-type doping properties of $\mathrm{ZnS}$ nanocrystals doped with single dopants of $\mathrm{N}$, P, or As and composite dopants of N:Ga, N:In, or N:Al. Using the local density approximation (LDA) method, we study the activity and doping efficiency of all dopants, and discuss the doping mechanisms and the compensation properties based on the calculated density of states of ZnS. Finally, p-type $\mathrm{ZnS}$ nanocrystals with enhanced doping concentration and efficiency are realized.

\section{Theoretical Model}

2.1. Local Density Approximation Theory (LDA). According to Schrodinger equation in quantum mechanics,

$$
H \Psi=E \Psi,
$$




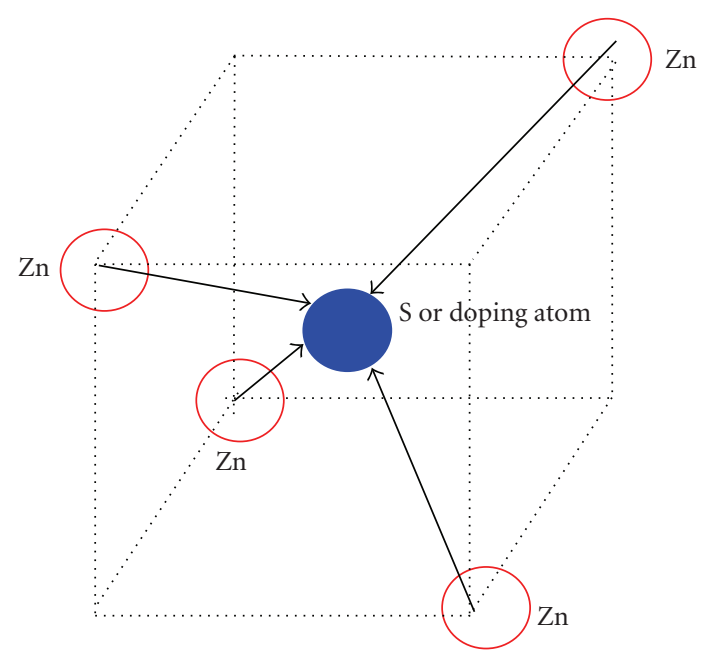

Figure 1: (a) A schema of $\mathrm{ZnS}$ structure. The red circles and blue spheres stand for $\mathrm{Zn}$ and $\mathrm{S}$ atom, respectively.

where, $H$ is Hamiltonian operator, $E$ is the system energy, and $\Psi$ describes the state of the system with $N$ electrons.

$$
H=-\frac{1}{2} \nabla^{2}-\sum_{q} \frac{Z_{q}}{\left|\vec{r}-\vec{R}_{q}\right|}+\frac{\rho(\vec{r})}{\left|\vec{r}-\overrightarrow{r^{\prime}}\right|} d r^{\prime}+V_{x c}(\vec{r}) .
$$

The density of state (DOS) $\rho(r)$ of electrons can be written as $[1,11]$

$$
\begin{gathered}
\Psi_{i}^{k}(\vec{r})=e^{i \vec{k} \cdot \vec{r}} \sum_{g} c_{i}^{k}(g) e^{i \vec{k} \cdot \vec{r}}, \\
\rho(\vec{r})=\sum_{i} n_{i} \Psi_{i}^{*}(\vec{r}) \Psi(\vec{r}) .
\end{gathered}
$$

Equation (4) is a local-density approximation (LDA) of $\rho(r)$, by which the DOS of a doped ZnS cluster can be calculated.

2.2. Structure of $\mathrm{ZnS}$ and the Simulation Method. $\mathrm{ZnS}$ is characteristic of a zincblende structure with a lattice constant of $0.5046 \mathrm{~nm}$, as shown in Figure 1. Four $\mathrm{Zn}$ atoms are located at the corners of a cube forming a tetrahedron; an $\mathrm{S}$ atom is positioned at the zenith of the tetrahedron. For p-type doping, $\mathrm{S}$ atom is substituted with either $\mathrm{N}, \mathrm{P}$, or As single dopants from Column V to offer more vacancy. To decrease the compensation effect from $\mathrm{Zn}_{\text {int }}$ atoms, the composite dopants of N:Ga, N:In, or N:Al are used to codope $\mathrm{ZnS}$ nanocrystals as well. For a comparison, the density of state (DOS) and the electronic structures of $\mathrm{ZnS}$ nanocrystals with and without doping were investigated using LDA method. In the simulation, we adopt a Von Barth-Hedin exchange correlation potential with the parameters used by Von Barth and Hedin [15]. Brillouin zone integration was carried out for 84-k points in an irreducible wedge and for $24-\mathrm{k}$ points for doped crystals. For valence electrons, we employed $p$ and $d$ orbitals for $\mathrm{Zn}$ atoms and the outer most $s$ and $p$ orbitals for other atoms. From the calculated DOSs, we determined the valence bands, the impurity level and the doping concentration.

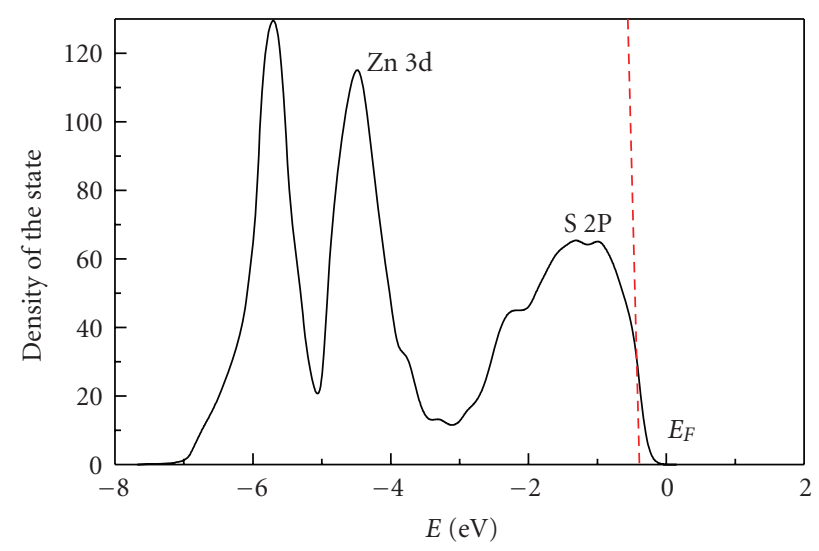

Figure 2: The density of state of $\mathrm{ZnS}$ nanocrystal without doping.

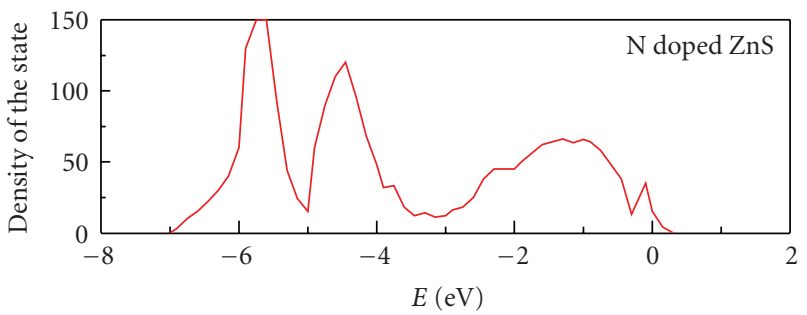

(a)

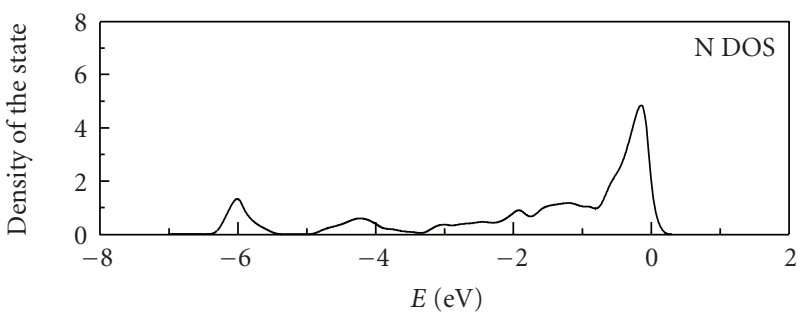

(b)

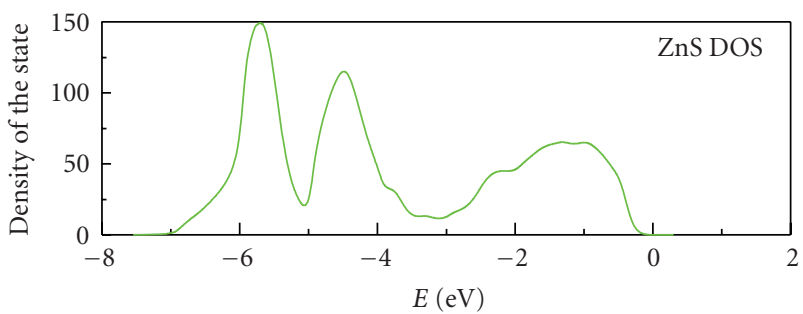

(c)

FIgure 3: (a) DOS of ZnS nanocrystals doped with $\mathrm{N}$ atom; (b) DOS of $\mathrm{N}$ atom; (c) DOS of the undoped $\mathrm{ZnS}$ nanocrystals.

\section{Results and Discussion}

3.1. Single Doping. For undoped $\mathrm{ZnS}$ nanocrystals, the calculated DOS is shown in Figure 2, where energy is measured from Fermi level $\left(E_{F}\right)$, thus the energy zero point is located on top of the valence band. As can be seen, there are three strong bands in the spectrum: the first one is from $-6.5 \mathrm{eV}$ to $-5.0 \mathrm{eV}$ with a strong character of $d$, mostly originating from the $d$ state of $\mathrm{Zn}$ atoms; the second one is a sharp 


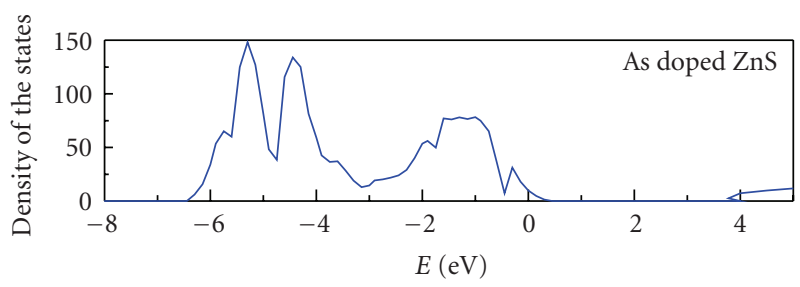

(a)

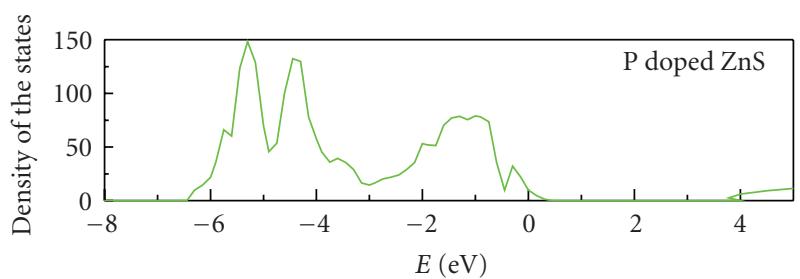

(b)

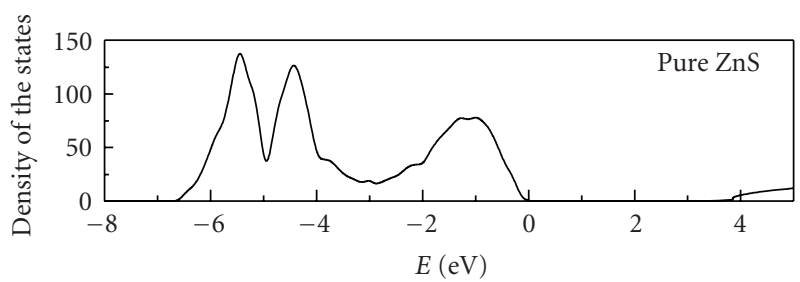

(c)

FIgURE 4: DOS spectra of $\mathrm{ZnS}$ nanocrystals doped with $\mathrm{P}$, and As atoms.

band located at $-5.1 \mathrm{eV}$ to $-4.0 \mathrm{eV}$, mainly contributed by the $3 p$ state $\mathrm{S}$ atoms; the third one in the range of $-3 \mathrm{eV}$ to $0 \mathrm{eV}$ is just nearby the valence band, resulting from a strong hybrid interaction between S $2 p$ and $\mathrm{Zn} 2 s$ states. The hybrid interaction occurs because the $3 s, 3 p$ states of $S$ atoms overlap with $4 s$ state of $\mathrm{Zn}$ atoms, leading to the $s$ and $p$ states of $\mathrm{Zn}$ atoms shifting to $S$ sites, along with charges are transferred from $\mathrm{Zn}$ atoms to $\mathrm{S}$ atoms.

For $\mathrm{N}$ doped $\mathrm{ZnS}$ nanocrystals, the DOS spectrum is shown in Figure 3(a). For comparison, the DOSs of single $\mathrm{N}$ atom and the undoped $\mathrm{ZnS}$ are shown in Figures 3(b) and $3(\mathrm{c})$, respectively. Clearly, in additional to the three bands of the undoped $\mathrm{ZnS}$, after doping a small narrow band at $-0.1 \mathrm{eV}$ appears on top of the valence band. The narrow band is introduced by $\mathrm{N}$ impurities, termed as an acceptor level. From the small band, we can estimate the relative doping density of $\mathrm{N}$ to be $10^{13} \mathrm{~cm}^{-3}$. It shows that ZnS nanocrystals doped with single $\mathrm{N}$ have low doping concentration and efficiency. This may be caused by the expelling effect of holes between the valence band and $\mathrm{N}$ impurities. The expelling force will localize the state of $\mathrm{N}$ on top of the valence band, leading to $\mathrm{N}$ atoms hard to ionize. In addition, the doping efficiency is affected by the compensation action of $\mathrm{Zn}_{\text {int }}$ atoms, which gives rise to multi ionizations: the first and the second ionizing energies of $\mathrm{Zn}_{\text {int }}$ are $0.05 \mathrm{eV}$ and $0.2 \mathrm{eV}$. They offer two donor states that can compensate the acceptors. Thus, the doping efficiency is not high.

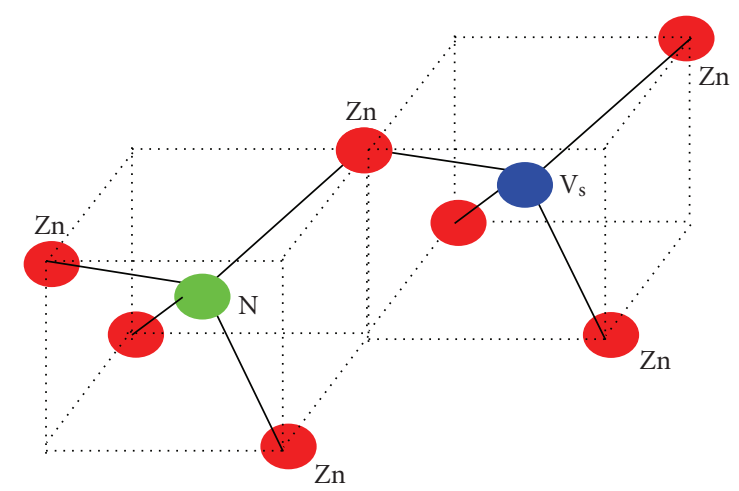

Figure 5: A schematic of complex defects in ZnS structure, it involves two unit cells.

For P and As dopants, similarly, a narrow acceptor level is introduced on top of the valence band of $\mathrm{ZnS}$, as shown in Figures 4(a) and 4(b), respectively. Also, because of the strong expelling interaction between $2 p$ states of $\mathrm{P}$ or As and $\mathrm{Zn}$ atoms, the acceptor levels are localized nearby $E_{F}$ level. Thus, the activity of the dopants is depressed, and the doping efficiency decreases as well.

For the doped structures of the three dopants, here referred to as $\mathrm{N}_{S}, \mathrm{P}_{\mathrm{S}}$, and $\mathrm{As}_{\mathrm{s}}$, we found that $\mathrm{N}_{S}$ is quite different from those of $\mathrm{P}_{\mathrm{S}}$ and $\mathrm{As}_{\mathrm{S}}$. An $\mathrm{N}_{\mathrm{S}}$ atom is positioned at the center of the tetrahedron, and the structure remains symmetrical but its volume shrinks by $0.48 . \mathrm{P}_{\mathrm{S}}$ and $\mathrm{As}_{\mathrm{s}}$ atoms shift to the bottom of the relaxed structures by $0.11 \mathrm{~A}$ and $0.13 \mathrm{~A}$, respectively. The volume for $\mathrm{P}_{\mathrm{S}}$ shrinks by 0.13 but for $\mathrm{As}_{\mathrm{s}}$ is almost unchanged. The shifts for $\mathrm{P}_{\mathrm{S}}$ and $\mathrm{As}_{\mathrm{s}}$ cause some distortion in the relaxed structures, which low the symmetry of the doped structures. Thus, the structure of $\mathrm{N}_{\mathrm{S}}$ doped $\mathrm{ZnS}$ nanocrystals is the most stable one.

For further increasing the doping concentration of single species, we found that the doping efficiency changes little, that is, the doping efficiency is not limited by the doping concentration but the expelling effect and the compensation action. The latter will become dominative as the doping concentration increases.

$\mathrm{Zn}$ atoms very easily deviate from the lattice sites to become interstitial $\mathrm{Zn}_{\text {int }}$ atoms, which may combine with dopants to form complex defects. For N-doped ZnS, the complex defect is denoted as $\mathrm{N}_{S}-\mathrm{Zn}_{\text {int }}$, where $\mathrm{N}_{S}$ means an $\mathrm{N}$ atom replacing an $\mathrm{S}$ atom in the structure. On the other hand, for heavily p-type doped $\mathrm{ZnS}$ nanocrystal, to achieve a stable structure some adjacent point defects may combine together to form complex defects as well, such as $\mathrm{N}_{\mathrm{S}}-\mathrm{Zn}-\mathrm{V}_{\mathrm{S}}$, where $\mathrm{N}_{S}$ and $\mathrm{V}_{S}$ atoms are bonded through a $\mathrm{Zn}$ atom. We therefore have two complex defect models: $N_{S}-Z_{\text {int }}$ and $N_{S^{-}}$ $\mathrm{Zn}-\mathrm{V}_{\mathrm{S}}$. The latter is associated with two neighboring $\mathrm{ZnS}$ unit cells, as shown in Figure 5. These complex defects are different from the point defects. $\mathrm{N}_{\mathrm{S}}-\mathrm{Zn}-\mathrm{N}_{\mathrm{S}}$ produces a deep acceptor level while $\mathrm{N}_{\mathrm{S}}-\mathrm{Zn}_{\text {int }}$ forms a donor level in the band gap of ZnS, both play an important compensation action for p-type doping of $\mathrm{ZnS}$, which makes the p-type doping of $\mathrm{ZnS}$ more complex $[16,17]$. 


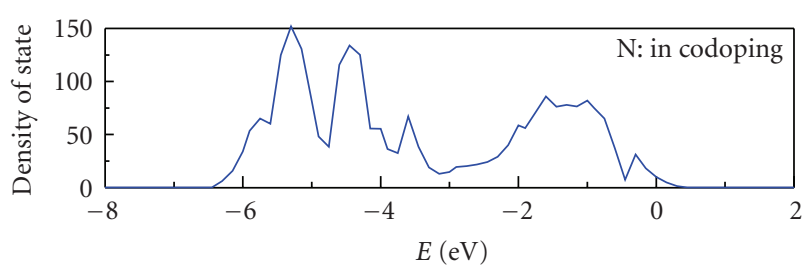

(a)

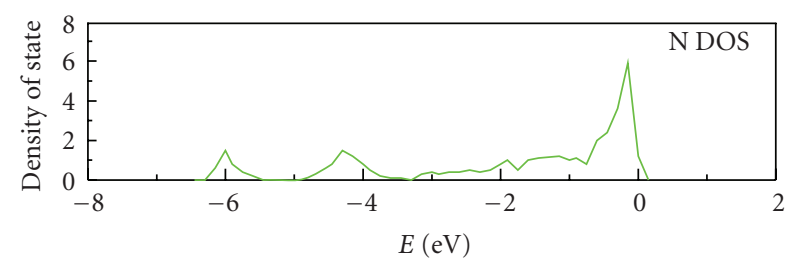

(b)

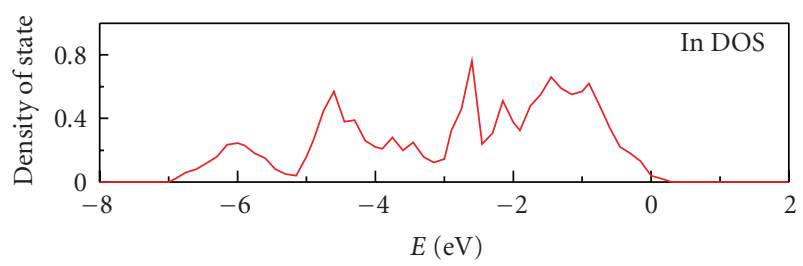

(c)

Figure 6: (a) DOS of ZnS nanocrystals codoped with N:In elements; (b) DOS of N atom; (c) DOS of In atom.

Above all, due to the expelling and compensation effects, single dopants in Column $\mathrm{V}$ cannot achieve the p-type doping for ZnS. The compensation effect is an inherent behavior of $\mathrm{ZnS}$, which can be depressed at low doping concentration. From the point of energy view, the system energy falls with the expelling potential decreasing, and then the compensation is depressed as well. To achieve the p-type doping, therefore, it is necessary to enhance the activity of the acceptors and decrease the expelling effect.

3.2. Codoping. Yamamoto et al. [11] studied the p-type doping properties for $\mathrm{ZnO}$ with various dopants using LDA, and found that it could be achieved with ally dopants from Column III-V. ZnS will have a similar doping behavior to $\mathrm{ZnO}$ for both of them belonging to II-VI semiconductors. Hence, we apply the composite dopants, $\mathrm{N}: \mathrm{Ga}, \mathrm{Al}$, or In, to codope ZnS Ncs. Figure 6(a) gives the DOS spectrum for ZnS Ncs doped with N:In. As references the DOSs for single $\mathrm{N}$ and In elements are shown in Figures 6(b) and 6(c), respectively. Apparently, the DOS of the codoped $\mathrm{ZnS}$ is different from that of the single species. Besides the three bands originated from $\mathrm{ZnS}$, a new band at $-3.67 \mathrm{eV}$, closely to In site appeared. Moreover, the acceptor level on top of the valence band becomes much wider than that of the single species. The new band results from the strong interaction between $\mathrm{N}$ $2 p$ and In $3 s$ states, meaning a strong coupling action between $\mathrm{N}$ and In atoms. This coupling action just cancels the expelling effect between $\mathrm{N} 2 p$ and $\mathrm{Zn} 3 p$ states, and increases their orbitals hybridizing. The decreased expelling

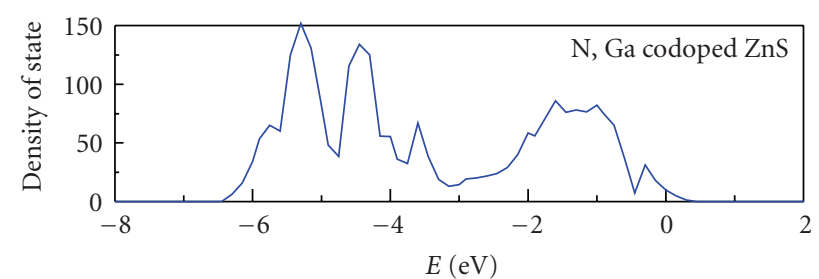

(a)

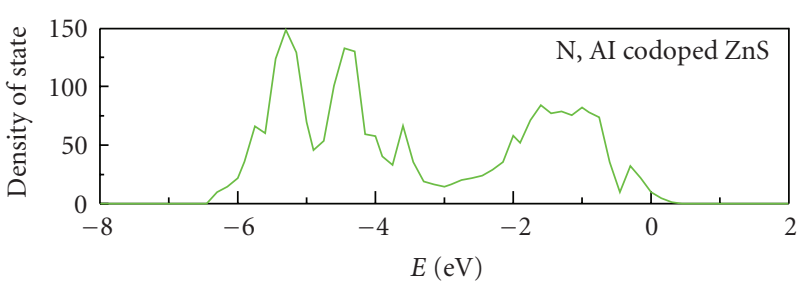

(b)

FIGURE 7: (a) DOS of ZnS nanocrystals codoped with N:Ga elements. (b) DOS of ZnS nanocrystals codoped with N:Al elements.

lowers the system energy and the compensation effect; the relative doping concentration of $\mathrm{N}: \mathrm{Ga}$ can be enhanced to $10^{16} \mathrm{~cm}^{-3}$. As a result, the doping efficiency of $\mathrm{N}$ is improved.

For $\mathrm{N}: \mathrm{Ga}$ and $\mathrm{N}: \mathrm{Al}$ codopants, the DOSs are shown in Figures $7(\mathrm{a})$ and $7(\mathrm{~b})$, respectively. Similarly, a small new band is located at $-3.70 \mathrm{eV}$ resulting from the interaction between $\mathrm{N} 2 p$ and $\mathrm{Ga}$ or $\mathrm{Al} 3 s$ states. And the acceptor levels on top of valence bands become wider as well. Apparently, the dopants of $\mathrm{Ga}, \mathrm{Al}$, or In play a role for activating single species than recombination centers. Among the three dopants, Ga shows the best doping efficiency. Finally, using the composite dopants of $\mathrm{N}$ with Column III elements, p-type ZnS with high doping efficiency is completed.

\section{Conclusions}

Using the LDA method, we investigate the p-type doping properties of $\mathrm{ZnS}$ nanocrystals doped with both single dopants N, P, or As and the composite dopants N:Ga, In, or Al. For single dopants, the doping efficient is not very high because of the strong compensation of interstitial $\mathrm{Zn}_{\text {int }}$ and the expelling potential between $\mathrm{Zn}$ atom and $\mathrm{N}$ impurity, which low the solid concentration in ZnS nanocrystals and restrain the active of the acceptors. For the composite dopants $\mathrm{N}: \mathrm{Ga}$, In, or $\mathrm{Al}$, the expelling effect between $\mathrm{N}$ and $\mathrm{Zn}$ atoms decreases, and the concentration of $\mathrm{N}$ impurity is enhanced. Finally, p-type ZnS nanocrystal with high doping efficiency is achieved.

\section{Acknowledgments}

The research work was supported in part by the National Natural Science Foundation (nos. 60776004, 60976071) and the Scientific Project of Shaoxing City (no. 2009A21054). 


\section{References}

[1] T. Yamamoto, S. Kishimoto, and S. Iida, "Materials design for p-type $\mathrm{ZnS}$ with blue Ag emission by triple-codoping method," Physica Status Solidi B, vol. 229, no. 1, pp. 371-375, 2002.

[2] H.-J. Jeon and Y. S. Kang, "Synthesis of Zns: $\mathrm{Mn}^{2+}$ nanocrystals and luminescence properties of ldpe film containing Zns: $\mathrm{Mn}^{2+}$," International Journal of Nanoscience, vol. 1, no. 56, pp. 495-499, 2002.

[3] Y. Y. Chen, J. G. Duh, B. S. Chiou, and C. G. Peng, "Luminescent mechanisms of $\mathrm{ZnS}: \mathrm{Cu}: \mathrm{Cl}$ and $\mathrm{ZnS}: \mathrm{Cu}: \mathrm{Al}$ phosphors," Thin Solid Films, vol. 392, no. 1, pp. 50-55, 2001.

[4] J. R. Heath, "The chemistry of size and order on the nanometer scale," Science, vol. 270, no. 5240, pp. 1315-1316, 1995.

[5] G. D. Yuan, W. J. Zhang, J. S. Jie et al., "p-type ZnO nanowire arrays," Nano Letters, vol. 8, no. 8, pp. 2591-2597, 2008.

[6] H. S. Kang, B. D. Ahn, J. H. Kim et al., "Structural, electrical, and optical properties of p-type $\mathrm{ZnO}$ thin films with $\mathrm{Ag}$ dopant," Applied Physics Letters, vol. 88, no. 20, Article ID 202108, 2006.

[7] G. D. Yuan, Z. Z. Ye, L. P. Zhu et al., "Control of conduction type in Al- and N-codoped $\mathrm{ZnO}$ thin films," Applied Physics Letters, vol. 86, no. 20, Article ID 202106, pp. 1-3, 2005.

[8] T. Kezuka, M. Konishi, T. Isobe, and M. Senna, "Preparation and properties of nanocrystalline $\mathrm{ZnS}: \mathrm{Mn}$-polymer composite films," Journal of Luminescence, vol. 87, pp. 418-420, 2000.

[9] L. Svob, C. Thiandoume, A. Lusson, M. Bouanani, Y. Marfaing, and O. Gorochov, "p-type doping with $\mathrm{N}$ and $\mathrm{Li}$ acceptors of ZnS grown by metalorganic vapor phase epitaxy," Applied Physics Letters, vol. 76, no. 13, pp. 1695-1697, 2000.

[10] S. Kishimoto, A. Kato, A. Naito, Y. Sakamoto, and S. Iida, "Attempts of homo p-n junction formation in $\mathrm{ZnS}$ by impurity Co-doping with vapor phase epitaxy," Physica Status Solidi B, vol. 229, no. 1, pp. 391-393, 2002.

[11] T. Yamamoto, S. Kishimoto, and S. Iida, "Control of valence states for ZnS by triple-codoping method," Physica B, vol. 308310, pp. 916-919, 2001.

[12] S. Kishimoto, T. Hasegawa, H. Kinto, O. Matsumoto, and S. Iida, "Effect and comparison of co-doping of $\mathrm{Ag}, \mathrm{Ag}+\mathrm{In}$, and $\mathrm{Ag}+\mathrm{Cl}$ in $\mathrm{ZnS}: \mathrm{N} / \mathrm{GaAs}$ layers prepared by vapor-phase epitaxy," Journal of Crystal Growth, vol. 214, pp. 556-561, 2000.

[13] G. D. Yuan, W. J. Zhang, W. F. Zhang, et al., "p-type conduction in nitrogen-doped ZnS nanoribbons," Applied Physics Letters, vol. 93, no. 21, p. 3, 2008.

[14] L. Svob, C. Thiandoume, A. Lusson, M. Bouanani, Y. Marfaing, and O. Gorochov, "p-type doping with $\mathrm{N}$ and $\mathrm{Li}$ acceptors of ZnS grown by metalorganic vapor phase epitaxy," Applied Physics Letters, vol. 76, no. 13, pp. 1695-1697, 2000.

[15] U. Von Barth and L. Hedin, "A local exchange-correlation potential for the spin polarized case. I," Journal of Physics C, vol. 5, no. 13, article no. 012, pp. 1629-1642, 1972.

[16] P. Schröer, P. Krüger, and J. Pollmann, "First-principles calculation of the electronic structure of the wurtzite semiconductors $\mathrm{ZnO}$ and ZnS," Physical Review B, vol. 47, no. 12, pp. 6971-6980, 1993.

[17] A. V. Singh, R. M. Mehra, A. Wakahara, and A. Yoshida, "p-type conduction in codoped $\mathrm{ZnO}$ thin films," Journal of Applied Physics, vol. 93, no. 1, pp. 396-399, 2003. 

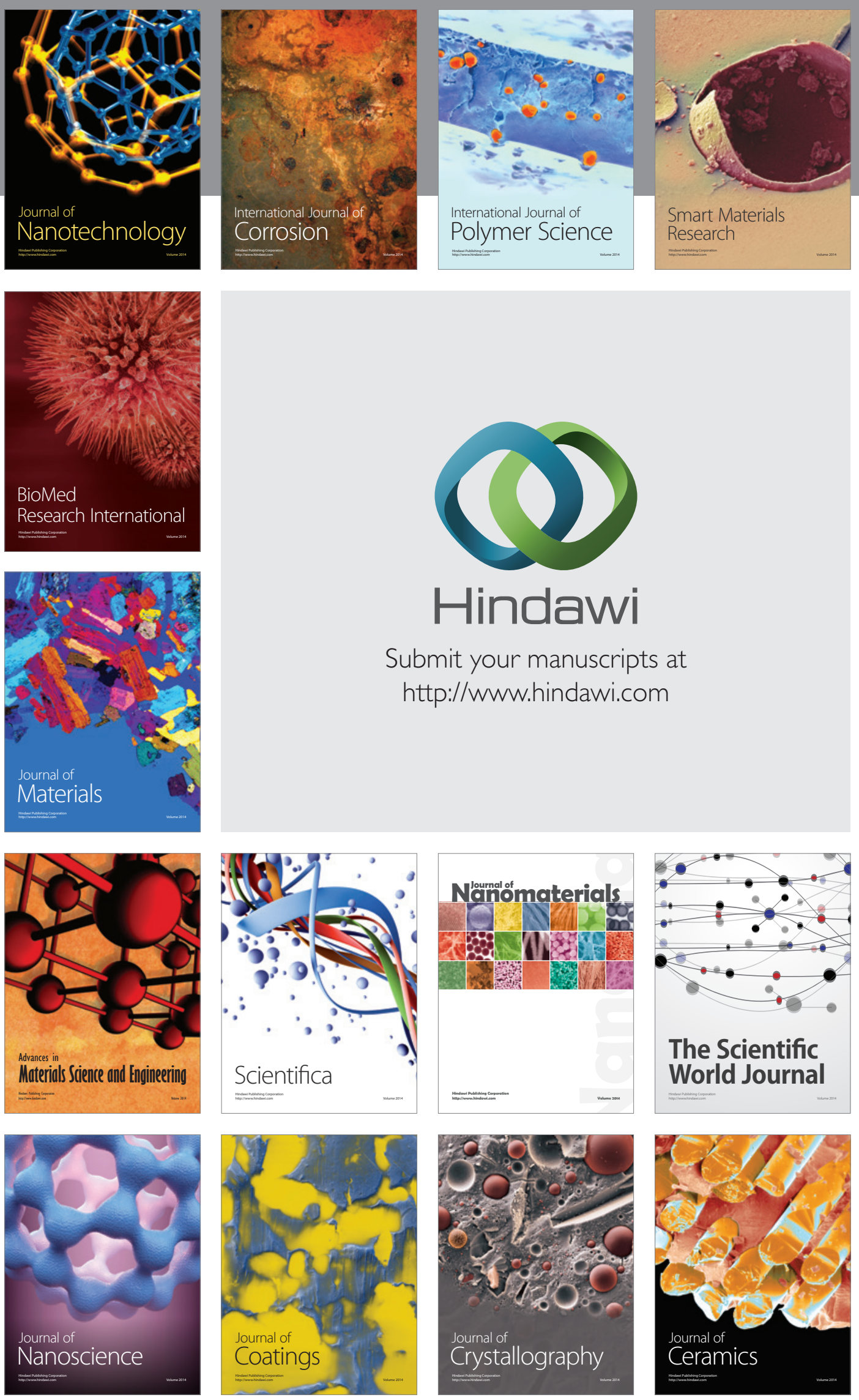

The Scientific World Journal

Submit your manuscripts at

http://www.hindawi.com

\section{World Journal}

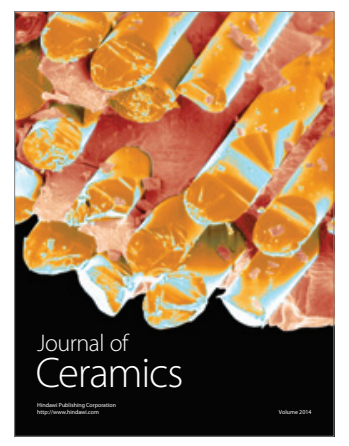

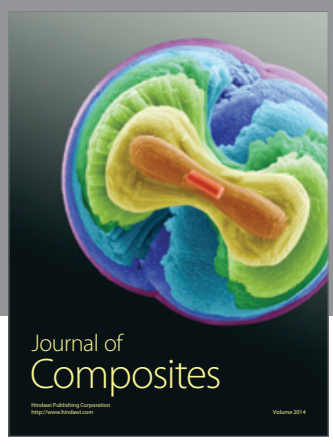
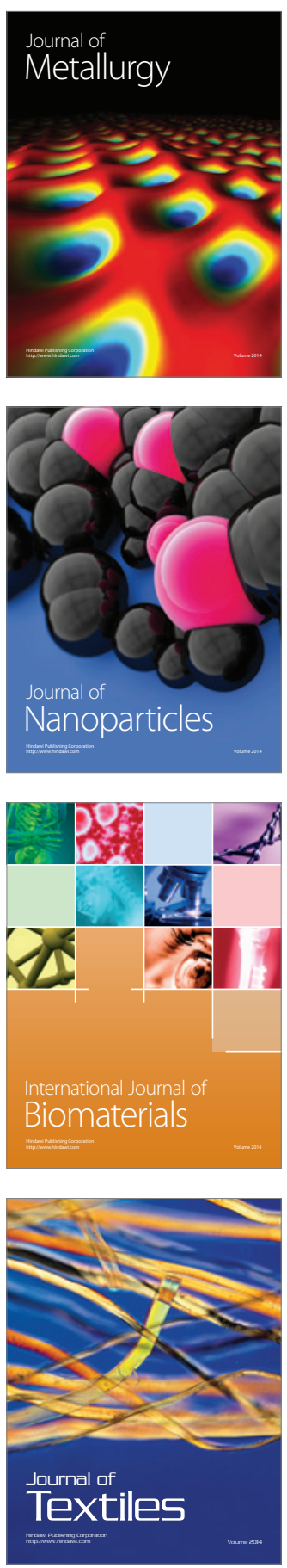